\title{
Obesity: A Potential Pandemic for the 21st Century among the Youths in Zimbabwe
}

\author{
Esther Mufunda1, Lynah Makuyana ${ }^{2}$ \\ ${ }^{1}$ Department of Health Sciences, Faculty of Science and Technology, Zimbabwe Open University, Harare, \\ Zimbabwe \\ ${ }^{2}$ Department of Health Sciences, Faculty of Science, Bindura University of Science Education, Bindura, \\ Zimbabwe \\ Email: esthermufunda@yahoo.co.uk,essie.mufunda8@gmail.com, \\ Imakuyana@buse.ac.zw, lynahma@gmail.com
}

Received 1 February 2016; accepted 25 April 2016; published 29 April 2016

Copyright (C) 2016 by authors and Scientific Research Publishing Inc.

This work is licensed under the Creative Commons Attribution International License (CC BY). http://creativecommons.org/licenses/by/4.0/

(c) (i) Open Access

\begin{abstract}
Background: Obesity is now reported as an epidemic in many developed countries, and it is an emerging public health concern in developing, transitional, and newly developed countries. The incidence of obesity increases during adolescence and persists into adulthood and becomes irreversible. In addition to biological causes like inheritance, cultural factors (such as dietary knowledge, attitudes and behaviours), socio-demographic factors may also play a central role in the etiology of obesity. The aim of the study was to describe young adults' knowledge and perceptions about obesity, with a focus on comprehensibility and meaningfulness of obesity in their daily lives and its health implications. Methods: A cross-sectional descriptive design was used with 96 participants aged 18 - 35 years. The respondents' body mass indices (BMI) were calculated from self-reported weights and heights. Descriptive analytical, statistical methods were used for data analysis. Results: The youths had good knowledge about obesity, its causes and associated complications. Generally, negative attitudes toward obesity were reported. Some perceived obesity as the ideal body image among today's youths while others perceived obesity as something that was beyond their control. Identified knowledge gaps were in the area of obesity and nutrition knowledge, food preferences and implications to health. Knowledge deficit about obesity might lead to poor health-related behaviours with its associated complications. Conclusion: There is a need to intensify community-focused health education as a preventive strategy to empower the youths to take charge of their health and change their perceptions about obesity.
\end{abstract}

\section{Keywords}

Obesity, Pandemic, Perceptions, Youths, Zimbabwe 


\section{Introduction}

Obesity has reached epidemic proportions in many countries around the world. It is now an epidemic health problem in many developed countries, and it is an emerging public health concern in developing, transitional, and newly developed countries [1]. Its prevalence has increased dramatically in the last decades both in children and adults and is now considered as a major health problem. It has been projected that there are currently 2.3 billion overweight people aged 15 years and above, and that there will be over 700 million obese people worldwide by 2015 [2].

The increase in the prevalence of diabetes parallels that of obesity and both are emerging pandemics in the 21 st century. Some experts call this dual epidemic "diabesity" [3]. Due to increased dietary changes, reduction in physical activity and increased obesity, it is estimated that the prevalence of diabetes will triple within the next 25 years [4] [5]. Obesity represents a serious threat to health through its association with conditions such as type 2 diabetes mellitus, coronary heart disease and certain types of cancers [6]. Both obesity and type 2 diabetes are major public health problems throughout the world and are associated with significant potentially life-threatening co-morbidities and enormous economic costs [3]. People who are obese more than $20 \%$ over their ideal body weight for their height, have insulin resistance and are at particularly high risk of developing type 2 diabetes and its related medical problems.

Obesity arises from an energy imbalance whereby energy intake exceeds energy expenditure. Increased intake of foods that are high in energy and fat, low physical activity and high levels of inactivity are suspected to be major contributors to rising levels of obesity [6]. In addition to biological influences on obesity, cultural factors such as dietary knowledge, attitudes and behaviours and socio-demographic factors may play a central role in the aetiology of obesity [7]. The incidence of obesity increases during adolescence [8] [9] and tends to persist into adulthood [9] and becomes irreversible. Dealing with obesity either through prevention or treatment requires modification of one or both components of energy balance. Approaches to weight management (including a functional food approach) therefore can target multiple aspects of the energy balance systems: food intake, energy expenditure and energy storage [10].

Body Mass Index (BMI), a measure commonly used to define obesity and assess adiposity, is an indicator of relative weight for height (weight in kilograms divided by the square of height in meters $=\mathrm{kg} / \mathrm{m}^{2}$ ). It is frequently used as a surrogate for the crude assessment of excess body fat and to classify underweight, overweight and obesity in adults. Obesity is defined as a BMI $\geq 30.0 \mathrm{~kg} / \mathrm{m}^{2}$ [11]. BMI can be used to estimate the prevalence of obesity within a population (but not central obesity) and to identify individuals and groups at increased risks of morbidity and mortality. Since BMI can be considered to provide the most useful, albeit crude population-level measure of obesity [11], it enables priorities to be identified for intervention at either individual or community levels. The majority of data available relates BMI to morbidity and mortality [12]. While BMI is obtained relatively easily, it does not provide information about body composition (i.e. body fat $\mathrm{v}$. fat-free mass). Although body composition can be assessed accurately in the laboratory, these techniques are not readily available to the general population and those that are available to the general population (such as bioelectrical impedance and skin fold thickness) are not considered to be highly accurate or precise [13].

Throughout most of human history, weight gain and fat storage have been viewed as signs of health and prosperity [11]. Today, however as standards of living continue to rise, weight gain and obesity are posing a growing threat to health in countries all over the world. Obesity is considered a major risk factor not only for type 2 diabetes, lipid disorders and hypertension, but also for coronary heart disease and certain cancers [14], asthma, arthritis [15], increased incidence of low sperm concentration and low progressively motile sperm count, resulting in infertility [16].

Obesity is therefore a global epidemic that is associated with increased morbidity and mortality and imposes an enormous burden on individuals and public health. The emerging problems of obesity and associated chronic diseases are exacerbated as increasingly urbanized populations adopt diets with higher saturated fat in addition to lower fruit and vegetable intakes than was consumed traditionally. Healthy eating, exercise habits and a positive body image need to be developed and nurtured at younger ages across ethnic groups [17]. There is therefore need to intensify preventive, treatment and control measures of obesity amongst the youths in both the developed and the developing countries in order to reduce medical costs, mortality and morbidity.

In the United States, the prevalence of obesity has increased dramatically in the last decades both in children and adults and is now considered a major health problem. It has been reported that over $60 \%$ of the adult population is overweight or obese [18], and thus at increased risk of developing type 2 diabetes and cardiovascular 
diseases [19]. While obesity and diabetes are inheritable and associated with a complex aetiology, diet clearly plays an important role both in the development and management of these diseases. There is interest in functional foods that could help in the prevention and/or management of obesity and type 2 diabetes [10].

The rate of increase of obesity in the US population has led many to label this public health threat as an epidemic. This is supported by data from the National Health and Nutrition Examination Surveys [20] and by data from the Behavioural Risk Factor Surveillance System [15]. It is anticipated that as a result of the substantial rise in the prevalence of obesity and its life-shortening complications such as diabetes, life expectancy in USA at birth and at older ages could level off or even decline within the first half of this century [21]. Obesity, and mainly its abdominal form, is considered a major risk factor not only for Type 2 diabetes, lipid disorders and hypertension but also for coronary heart disease and certain cancers [14] like endometrial, breast, and colon, besides its emotional, social and psychological ramifications.

The prevalence of childhood and youth overweight/obesity has also increased considerably in recent years in the sub-Saharan region [22]. A previous study in Tanzania, reported that obesity was higher among middle-aged urban dwellers compared to their rural counterparts with a prevalence rate of $13 \%$ for men and $36 \%$ among women [23] [24]. Higher prevalence of obesity among women has also been noted in South Africa, with the highest prevalence among urban black women [25] and a prevalence of $13.3 \%$ in Cameroon [26]. With the rise in socio-economic status, urbanization, and diminishing physical activity, the prevalence of obesity has also increased in Botswana, Namibia and Zimbabwe [27].

Although perceptions about obesity differ from country to country, it has been reported that an appropriate perception of one's own weight is important for improved weight control behavior [27]. The relationship between BMI and body dissatisfaction can be influenced by ethnicity with different standards of beauty and, consequently, different desire to be more or less thin [17] [29]. In developed countries, a thin body is an ideal and preferred model among females [30] whereas in developing countries, a heavier body is preferred, although there is a shift towards a thin body among people of higher class [31]. Students in Ghana more often rated larger body sizes as ideal for both males and females and also assumed that these larger sizes were held as ideals in society as a sign of happiness, respect and wealth for females [32], so did some Ghanaian males [33]. Similar opinions were held by many people in a Tanzanian study who also preferred to be either overweight or obese so as not to be suspected of having HIV and AIDS [24], while the Moorish women of Mauritania and the Moroccan Sahraoui women still value weight and undergo social and cultural pressures in order to maintain their overweight [33].

Health risk knowledge has been identified as a key to making informed decisions regarding healthy lifestyle choices [5], as well as the appropriate perception of one's body weight for improved weight control behaviour [28]. Understanding the knowledge, attitudes and behaviours surrounding dietary and physical activity patterns as well as body size can play an important role in guiding interventions strategies aimed at maintaining energy balance and reduce obesity prevalence [6].

The results of a study to determine whether obesity was a problem in Zimbabwe suggested that obesity was not a problem in adult Black Africans of Zimbabwe. Women, however, were overweight (BMI $\left.=25-30 \mathrm{~kg} / \mathrm{m}^{2}\right)$ and had larger mean waist circumferences, posing a greater risk of health problems associated with abdominal adiposity [35]. Despite a general increase of obesity in the Zimbabwean population, no studies have assessed peoples' knowledge and perceptions about obesity which is threatening to become a potential epidemic in the country. Risk factors such as dietary behaviour, life style factors (smoking and alcohol use), physical activity and psychosocial factors for overweight in low-income countries are not well-known [32]. It is however known that overweight and obesity are largely preventable with changes in life style and avoidance of sedentary habits and overconsumption of energy-dense foods [3].

This study therefore investigated the youths' knowledge and perceptions about obesity, with a focus on comprehensibility and meaningfulness of obesity in their daily lives and its health implications. It is hoped that an understanding of this selected group of people's knowledge and perceptions about obesity will help in designing appropriate preventive and promotive health education programmes that address obesity and other related chronic non-communicable diseases in Zimbabwe.

\subsection{Aim of the Study}

The aim of the study was to determine the youths' knowledge and perceptions about obesity and its health implications and further, to identify the youths' needs for education in prevention and control of obesity. 


\subsection{Theoretical Framework}

The revised Health Belief Model (RHBM) was used to underpin this study because it attempts to predict health-related behavior in terms of certain belief patterns. The model is an example of a Prevention Model that explores why some people who are free from illness take actions to avoid illness while on the other hand some people fail to do so [36]. It states that the perception of a personal health behavior threat is itself influenced by at least three factors: general health values, which include interest and concern about health; specific health beliefs about vulnerability to a particular health threat; and beliefs about the consequences of the health problem. This model was chosen in line with the main aim of this study since the researchers wanted to understand and predict why and under what conditions the youths would take preventive and control measure towards obesity. This theory stipulates that modifying factors (age, sex, and other socio-demographic variables) might influence youth to seek health related information that will enable them to avoid getting obese. This information will make them realize that the information is relevant to them (perceived susceptibility). The youths might then be motivated (cues to action) to comply and adopt healthy eating behaviours and engage in regular exercises (Figure 1).

Therefore, empowerment of the youths using acceptable health promotion strategies will be expected to change behaviour leading to adoption of healthy life-styles in relation to obesity prevention. Supportive environments and communities are fundamental in shaping the youths' choices, making healthier choices of food stuffs and regular physical activity the easiest choice which is available, accessible and affordable and therefore, preventing obesity.

\section{Methods and Materials}

\subsection{Study Design}

A descriptive cross- sectional study was conducted using a self-report questionnaire with 96 respondents aged 18 - 35 years and mean age of 23 years. The design enabled the disclosure of information on the different perspectives about obesity and further, to make inferences about possible relationships between the respondents' socio-demographic and obesity-related characteristics and their knowledge and perceptions about overweight and obesity.

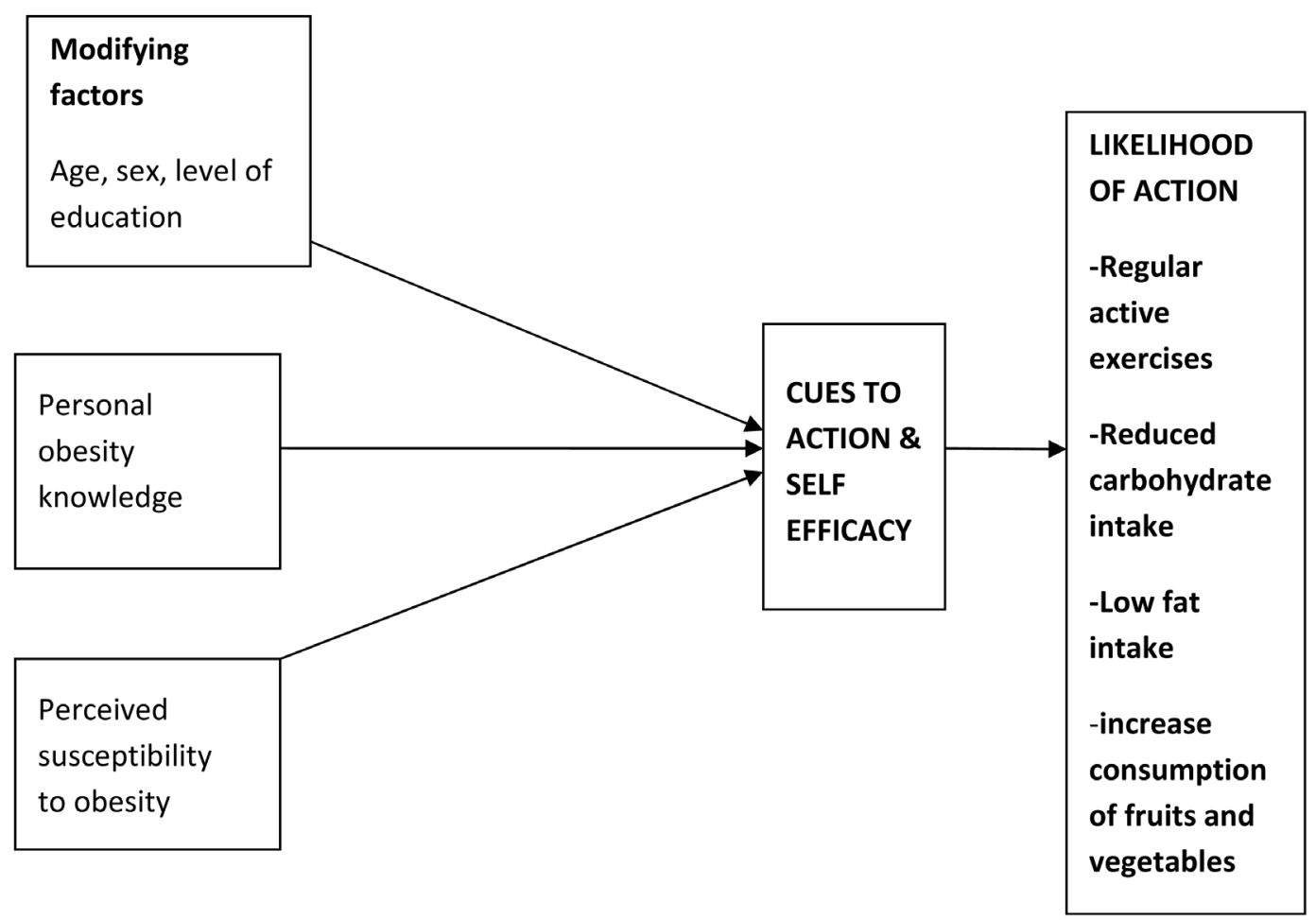

Figure 1. Theoretical proposition of the revised health belief model. 


\subsection{Study Population}

The study population comprised of students from a selected state owned university in Zimbabwe. The sample consisted of 96 youths, 49 females and 47 males aged 18 - 35 years and obtained through convenience sampling. The inclusion criteria required that the respondent be university students who were mentally sound to give informed consent and were conversant with English. Body size was not a limiting factor for eligibility to participate in the study.

\subsection{Data Collection Instrument}

Data were collected using a self- report questionnaire, developed by the investigator after a review of relevant literature and adoption of some questions from a validated (ORK-10) Obesity Risk Knowledge-10 scale questionnaire [5]. The questionnaire was peer- reviewed by two senior nurse lecturers in the department of Health Sciences.

The questionnaire was divided into two sections. Section A elicited the respondents' socio-demographic characteristics that included age, sex and level of education. Respondents were also asked to record their current heights and weights. A bathroom scale was also used to verify the respondents' weights in case they were not sure. Section B examined the respondents' knowledge on; obesity, nutrition and obesity-associated complications by ticking either (True/False) in appropriate boxes up to 61 items. Food preferences, food-related behaviours and their implications on health plus the respondents' perceptions towards their body images in relation to overweight and obesity were also elicited. The respondents' perceptions and attitudes towards their own weights were assessed using the following questions:

1) How do you feel about your own body weight?

2) If you were obese, would it affect you in any way? (Yes/No. Please explain your answer)

3) Does obesity affect your self-esteem? (Yes/No. Please explain your answer)

4) If you were obese, would it affect your social life? (Yes/No. Please explain your answer)

5) There is no need to worry about overweight or obesity as long as it is not causing any health problems. (True/ False)

6) If you were obese, would you make an effort to lose weight? (Yes/No). Explain your answer.

\subsection{Data Collection}

Data were collected between March and July 2015 by the investigators and two trained research assistants. The self-report questionnaire used in the study was piloted on six university students, after which minor modifications to the question arrangement, wording and meanings were made before being used on a larger sample described above. The questionnaire was in English (one of the three official languages in Zimbabwe) and it required 15 to 20 minutes to complete. The completed questionnaires were checked for completeness and collected soon after completion.

\subsection{Ethical Consideration}

The study was approved by the Ethics committee of the university that was used for the study. Written informed consent was obtained from each respondent in accordance with the Helsinki Declaration.

\subsection{Data Analysis}

Data were analyzed using SPSS (Version 20). Prior to analysis, all the data were assessed and screened for missing values before applying appropriate parametric and non-parametric statistics on the useable responses. (Chi squared and $t$-tests were used to statistically compare the data).Pearson's correlation was used to determine the association between the respondents' knowledge and BMI, body image, self perception and to analyze the strength and significance of the associations.

Obesity was defined using body mass indices (BMI) which were calculated from the respondents' self-reported weights and heights. Obesity was defined and graded on a scale according to WHO Classification of adult obesity (2000). Underweight (BMI $\left.<18.5 \mathrm{~kg} / \mathrm{m}^{2}\right)$; overweight $\left(\mathrm{BMI} \geq 25 \mathrm{~kg} / \mathrm{m}^{2}\right)$; Pre-obese $(25-30$ $\mathrm{kg} / \mathrm{m}^{2}$ ); class I obesity (BMI $30-35 \mathrm{~kg} / \mathrm{m}^{2}$ ); class II obesity (BMI $35-40 \mathrm{~kg} / \mathrm{m}^{2}$ ); class III obesity (BMI $\geq 40$ $\left.\mathrm{kg} / \mathrm{m}^{2}\right)$. Normal BMI $\left(18.5-24.9 \mathrm{~kg} / \mathrm{m}^{2}\right)$.

Knowledge levels were obtained by scoring the respondents' responses. Correct responses scored a point 
while incorrect and "don't know" responses scored zero points. Operationally, the total possible knowledge score was 61.A score of $<30.5$ was rated as poor knowledge; 30.5 - 37 (average knowledge); 38 - 45 (Good knowledge) and $\geq 46$ (very good knowledge).Knowledge gaps were identified by recording the questions that were incorrectly answered or where the respondent indicated "I don't know".

\section{Results}

\subsection{Respondents' Characteristics}

Table 1 summarizes the socio-demographic and obesity-related data of the respondents. A total of 96 respondents, 47 males (49\%) and 49 females (51\%) aged 18 - 35 years (mean, 23 years) participated in the study. Most of the respondents $44(46 \%)$ were between 18 - 22years. Almost a third of the respondents were first year students. Weight range was $45-105 \mathrm{~kg}$ (median $62 \mathrm{~kg}$ ); BMI $18.5-35.6 \mathrm{~kg} / \mathrm{m}^{2}$ (median $24.3 \mathrm{~kg} / \mathrm{m}^{2}$ ) and height $1.3-1.9 \mathrm{~m}$ (median $1.6 \mathrm{~m}$ ). More than half of the respondents, $53(55 \%)$ had a normal BMI $\left(18.5-24.9 \mathrm{kgm}^{2}\right)$, seven were underweight (BMI $\left.<18.5 \mathrm{~kg} / \mathrm{m}^{2}\right) ; 9(9 \%)$ were overweight $\left(\mathrm{BMI} \geq 25 \mathrm{~kg} / \mathrm{m}^{2}\right), 14(15 \%)$ were pre obese (BMI $25.00-29.9 \mathrm{~kg} / \mathrm{m}^{2}$ ) while the remainder, $13(14 \%)$ were obese (BMI $30.00-39.99 \mathrm{~kg} / \mathrm{m}^{2}$ ) (the 13 respondents who belonged to the last group of obesity included those in obese classes I \& II as shown in Table 1).

\subsection{Obesity-Related Knowledge}

Overall, $73.3 \% \pm 11.1 \%$ of the respondents correctly answered the items on the obesity knowledge test, mean of $48.4 \pm 4.6$. Three percent had "average" knowledge, 12 (13\%) had 'good' knowledge while the majority, 81 (84\%) had "very good" knowledge about obesity, its causes and related complications (see Table 2) below.

Table 1. Socio-demographic, overweight and obesity-related characteristics of the respondents.

\begin{tabular}{|c|c|}
\hline Variable & Frequency n (\%) \\
\hline \multicolumn{2}{|l|}{ Sex } \\
\hline Male & $47(49)$ \\
\hline Female & $49(51)$ \\
\hline \multicolumn{2}{|c|}{ University Educational level } \\
\hline First year & $58(60)$ \\
\hline Second year & $19(20)$ \\
\hline Final year & $19(20)$ \\
\hline \multicolumn{2}{|c|}{ Body Mass Index categories } \\
\hline $18.5-24.9 \mathrm{~kg} / \mathrm{m}^{2}$ (Normal BMI) & $53(55)$ \\
\hline$<18.5 \mathrm{~kg} / \mathrm{m}^{2}$ (Underweight) & $7(7)$ \\
\hline$\geq 25 \mathrm{~kg} / \mathrm{m}^{2}$ (Overweight) & $9(9)$ \\
\hline $25.00-29.99 \mathrm{~kg} / \mathrm{m}^{2}$ (Pre obese) & $14(15)$ \\
\hline $30.00-34.99 \mathrm{~kg} / \mathrm{m}^{2}$ (Obese class I) & $12(13)$ \\
\hline $35.00-39.99 \mathrm{~kg} / \mathrm{m}^{2}$ (Obese class II) & $1(1)$ \\
\hline
\end{tabular}

Table 2. Respondents' total knowledge about obesity.

\begin{tabular}{ccc}
\hline Knowledge scores (out of 61) & Frequency n (\%) & Description \\
\hline$<30.5$ & 0 & Poor \\
$30.5-37$ & $12(13)$ & Average \\
$38-45$ & $81(84)$ & Good \\
$\geq 46$ & Very good \\
\hline
\end{tabular}


Knowledge deficit (incorrectly answered items + "don't know" with a score above 50\%) was noted in questions related to the following: Definition of obesity ( $90 \%$ ); Causes of obesity (child birth $=68 \%$, family planning pills $=$ $61 \%$, hot dogs $=60 \%$, craving $=53 \%$ ); Obesity-related complications (diabetes mellitus $=56 \%$, infertility $=54 \%$, gout $=54 \%$, arthritis $=51 \%)($ see Table 3$)$.

The majority of the respondents, 85 (89\%) knew that low physical activity and high levels of inactivity increased the risk of obesity. Identified knowledge gaps were in the area of obesity and its predisposing factors, diet and food preferences and obesity-related complications.

\subsection{Association of Knowledge with Demographic and Obese-Related Characteristics}

Pearson's Chi-square test showed that knowledge about obesity was significantly associated with age $(p=0.002$, $95 \% \mathrm{CI})$ and one's BMI $(\mathrm{p}=0.012,95 \% \mathrm{CI})$ while feeling about one's weight was significantly associated with the BMI $(p=0.038,95 \% \mathrm{CI})$. No other associations were found between obesity-related knowledge and the other demographic and obesity-related characteristics of the respondents.

\subsection{Perceptions and Attitudes towards Obesity and Own Body Weight}

The results showed that the respondents had mixed perceptions and feelings towards overweight, obesity and their own body weight as summarized in Table 4 .

Table 3. Questions answered either incorrectly or "I don't know".

\begin{tabular}{|c|c|c|c|}
\hline \multicolumn{2}{|r|}{ Question } & Incorrectly answered (\%) & Don't know (\%) \\
\hline \multirow{2}{*}{\multicolumn{2}{|c|}{ 1. A person is considered to be obese when their BMI is... }} & 19 & 71 \\
\hline & & False & Don't know \\
\hline \multicolumn{4}{|c|}{ 2. Causes of obesity include the following: } \\
\hline a) & Childbirth & 66 & 2 \\
\hline b) & Family planning & 59 & 2 \\
\hline c) & Foods like hot dogs & 32 & 28 \\
\hline d) & Craving & 43 & 10 \\
\hline \multicolumn{4}{|c|}{ 3.Obesity related complications include: } \\
\hline a) & Diabetes mellitus & 53 & 3 \\
\hline b) & Arthritis & 44 & 7 \\
\hline c) & Infertility & 48 & 6 \\
\hline d) & Gout & 52 & 2 \\
\hline
\end{tabular}

Table 4. Respondents' perceptions and feelings about obesity.

\section{Explanations to Questions}

Frequency n (\%)

1. If you were obese, how would it affect you?

a) Activities like sports and outings, daily activities

$6(6)$

b) No need to worry because that is the way I am

$39(41)$

c) It causes diseases e.g. heart diseases

$28(29)$

d) Makes me uncomfortable (Self stigmatization)

$8(8)$

e) No explanations

$15(16)$

2. How would obesity affect your self esteem?

a) It makes me uncomfortable and less confident

b) Overweight/Obesity is the ideal body weight from an African perspective 32 (33)

c) Stigmatization by others

$21(22)$

d) No explanations

$6(6)$

3. How would obesity affect your social life?

$\begin{array}{ll}\text { a) Stigmatization } & 29 \text { (30) }\end{array}$

b) Won't be attracted to the opposite sex 11 (11)

$\begin{array}{ll}\text { c) Inability to participate in social activities } & 21(22)\end{array}$

\begin{tabular}{ll} 
d) Clothes won't fit well $2(2)$ \\
\hline
\end{tabular}

e) No need to worry, I like it that way $25(26)$

f) No explanations 6 (8)

4. If you were obese, would you make an effort to lose weight?

b) There is need to exercise and have a low fat diet $\quad 7$ (7)

c) Obesity is a problem that needs to be addressed 13 (14)

d) Obesity leads to stigmatization 7 (7)

e) No comments $36(38)$ 


\section{Discussion}

Obesity constitutes a major public health problem and a risk factor for many debilitating diseases that are a main cause of mortality and morbidity around the world. Weight control initiatives should attempt to influence people's weight-related knowledge as well as their perceptions and attitudes towards weight control. The main findings of this study showed that the majority $(90 \%)$ of the respondents did not know the minimum BMI for defining obesity, despite good knowledge about the comorbid conditions associated with obesity.

Over fifty percent of the youths in this study failed to recognize such chronic and debilitating diseases like diabetes mellitus and arthritis as possible obesity- related complications. Diabetes mellitus, particularly type 2 has been reported to be on the increase globally, reaching pandemic levels in low-income countries in sub- Saharan Africa [37]. Because of the close relationship between obesity and type 2 diabetes, an epidemic of diabetes is close behind the obesity epidemic [10], associated with increasing morbidity, mortality and socio-economic cost.

Furthermore, most of the youths failed to appreciate that obesity is caused by lifestyle factors like smoking and alcohol use and poor eating habits like food cravings and hot dogs that most university students commonly prefer to eat. This finding shows that the youths need to have a better understanding of the life-style causative factors of obesity which they can easily control through the adoption of healthy behaviours e.g. refraining from eating fatty foods while increasing active physical activity.

Previous studies have reported that the incidence of obesity increases during adolescence [8] and progresses into adulthood [9] as increasingly urbanized populations adopt diets with higher saturated fat in addition to lower fruit and vegetable intakes than was consumed traditionally. In this study, most of the respondents $53(55 \%)$ had normal BMI, while 23 (24\%) were overweight and 13 (14\%) were reported to be obese. The statistical significance between the respondents' age and knowledge about obesity means that the older youths were more knowledgeable about obesity than the younger ones. Similar findings were reported in a previous study in South Africa [38]. Health education about overweight and obesity must therefore be commenced at a young age (pre-adolescence) before the children become overweight. This can be achieved through school health programmes, which is a component of Primary Health Care in Zimbabwe. This will minimize the use of unhealthy weight control practices that might commonly be used by the youths for example, use of slimming/diet pills as reported by some respondents $38(40 \%)$ in this present study.

Despite a high prevalence of obesity among the youths who participated in this study, there was a tendency towards underestimation of overweight and obesity, similar to findings from other African countries [24] [31]-[34]. Some respondents, 33 (34\%) reported that obesity was not a problem while others perceived obesity as the ideal body weight preferred by the opposite sex from an African perspective. Similar findings were also reported from a study conducted in America where $44 \%$ of those who were overweight considered themselves attractive [7] [39]. These negative attitudes towards obesity show some degree of body shape and size dysphoria that might suggest the likelihood of some interest in appropriately framed obesity- reduction efforts in the obese youths who participated in this study.

\subsection{Limitations}

Although the cross-sectional design used in this study enabled the investigator to make inferences about possible relationships between the respondents' demographic characteristics and their knowledge and perceptions about overweight and obesity, it was not possible to draw inferences on the direction of the association and causal relationships. Moreover, the small sample size in this study is not representative of the youths in Zimbabwe as a whole, making it rather difficult to generalize the findings. The same study could be conducted using a bigger sample size. The assessment of body weight by relying on self-reported values of weights and heights can be under or overestimated and anthropometric techniques could have been included to evaluate weight status and body fat content [40].

\subsection{Recommendations}

The findings in this study have highlighted areas worthy of intervention in the battle against obesity. However, the impact of long term low self-esteem and stigmatization among some Zimbabwean youths with high BMI deserves further study. Additional research is also needed to define the most effective role of primary care providers including health education on prevention of obesity, diagnosis of cases, counseling and referral to specialists for further management. 


\section{Conclusion}

This study has shown strong findings for the association of knowledge about obesity and age and one's BMI, while feeling about one's weight was associated with their BMI. Future health promotion efforts should therefore be aimed at strengthening obesity prevention education during pre-adolescence period, taking into account, the attitudes and health behaviours of the communities. The obesity-related knowledge gaps highlighted in this study can be used to formulate appropriate intervention strategies in this and other population groups.

\section{Acknowledgements}

The authors thank Precious, Nombulelo Mzizi and Likwa Dube (BSc. Nursing students at Bindura University of Science Education) for their assistance with data collection.

\section{References}

[1] Kan, K. and Tsai, W. (2004) Obesity and Risk Knowledge. Journal of Health Economics, 23, 907-934. http://dx.doi.org/10.1016/j.jhealeco.2003.12.006

[2] Brophy, S., Cooksey, R., Gravenor, M.B., Mistry, R., Thomas, N., Lyons, R.A. and Williams, R. (2009) Risk Factors for Childhood Obesity at Age 5: Analysis of the Millennium Cohort Study. BMC Public Health, 9, 467. http://dx.doi.org/10.1186/1471-2458-9-467

[3] Yaturu, S. (2011) Obesity and Type 2 Diabetes. Journal of Diabetes Mellitus, 1, 79-95. http://dx.doi.org/10.4236/jdm.2011.14012

[4] Sobngwi, E., Mauvais-Jarvis, F., Vexiau, P., Mbanya, J.C. and Gautier, J.F. (2001) Diabetes in Africans. Diabetes Metabolism, 27, 628-634.

[5] Swift, J.A., Glazebrook, C. and Macdonald, I. (2006) Validation of a Brief, Reliable Scale to Measure Knowledge about the Health Risks Associated with Obesity. International Journal of Obesity, 30, 661-668. http://dx.doi.org/10.1038/sj.ijo.0803165

[6] Gordon-Larsen, P. (2001) Obesity-Related Knowledge, Attitudes, and Behaviours in Obese and Non-Obese Urban Philadelphia Female Adolescents. Obesity Research, 9, 112-118. http://dx.doi.org/10.1038/oby.2001.14

[7] Kumanyika, S. (1987) Obesity in Black Women. Epidemiological Reviews, 9, 31-50.

[8] Dietz, W.H. (1994) Critical Periods in Childhood for the Development of Obesity. American Journal of Clinical Nutrition, 59, 955-959.

[9] Serdula, M.K., Ivery, D., Freedman, R.J.C., et al. (1993) Do Obese Children Become Obese Adults? A Review of the Literature. Preventive Medicine, 22, 167-177. http://dx.doi.org/10.1006/pmed.1993.1014

[10] Hill, J.O. and Peters, J.C. (2002) Biomarkers and Functional Foods for Obesity and Diabetes. British Journal of Nutrition, 88, S213-S218. http://dx.doi.org/10.1079/bjn2002685

[11] WHO Technical Series (2000) Obesity: Preventing and Managing the Global Epidemic. Report of a WHO Consultation. World Health Organization Technical Report Series, 894, 1-253. http://www.who.int/mediacentre/factsheets/fs311/en/

[12] National Institutes of Health (1998) Clinical Guidelines on the Identification, Evaluation, and Treatment of Overweight and Obesity in Adults-The Evidence Report. Obesity Research, 6, 51S-210S.

[13] Lohman, T.G. (2001) Body Composition. In: Fairburn, C. and Brownell, K., Eds., Eating Disorders and Obesity: A Comprehensive Handbook, 2nd Edition, Guilford, New York, 62-66.

[14] Hainer, V. and Aldhoon-Hainerová, I. (2013) Obesity Paradox Does Exist. Diabetes Care, 36, S276-S281. http://dx.doi.org/10.2337/des13-2023

[15] (a) Mokdad, H., Bowman, B.A., Ford, E.S., Vinicor, F., Marks, J.S. and Koplan, J.P. (2001) The Continuing Epidemics of Obesity and Diabetes in the United States. JAMA, 286, 1195-1200. http://dx.doi.org/10.1001/jama.286.10.1195 (b) Mokdad, A.H., Ford, E.S., Bowman, B.A., Dietz, W.H., Vinicor, F., Bales, V.S. and Marks, J.S. (2003) Prevalence of Obesity, Diabetes, and Obesity-Related Health Risk Factors, 2001. JAMA, 289, 76-79. http://dx.doi.org/10.1001/jama.289.1.76

[16] Hammoud, A.O., Wilde, N., Gibson, M., Parks, A., Carrel, D.T. and Meikle, A.W. (2007) Male Obesity and Alteration in Sperm Parameters. Fertility and Sterility, 90, 2222-2225.

[17] Fitzgibbon, M.L., Blackman, L.R. and Avellone, M.E. (2000) The Relationship between Body Image Discrepancy and Body Mass Index across Ethnic Groups. Obesity Research, 8, 582-589. http://dx.doi.org/10.1038/oby.2000.75

[18] Mann, A., Thompson, A., Robbins, N. and Blomkalns, A.L. (2014) Localization, Identification, and Excision of Mu- 
rine Adipose Depots. JoVE (Journal of Visualized Experiments), No. 94, e52174-e52174.

[19] Ogden, C.L., Carroll, M.D., Kit, B.K. and Flegal, K.M. (2014) Prevalence of Childhood and Adult Obesity in USA, 2011-2012. JAMA, 311, 806-814. http://dx.doi.org/10.1001/jama.2014.732

[20] National Centre for Health Statistics (1999) Prevalence of Overweight and Obesity among Adults: United States (Electronic Citation). http://www.cdc.gov/nchs/products/pubs/pubd/hestats/obese/obsc99.htm

[21] Olshansky, S.J., Passaro, D.J., Hershow, R.C., Layden, J., Carnes, B.A., Brody, J. and Ludwig, D.S. (2005) A Potential Decline in Life Expectancy in the United States in the 21st Century. New England Journal of Medicine, 352, 11381145 .

[22] Muthuri, S.K., Francis, C.E., Wachira, L.M., LeBlanc, A.G., Sampson, M., Onywera, V.O. and Tremblay, M.S. (2014) Evidence of an Overweight/Obesity Transition among School-Aged Children and Youth in Sub-Saharan Africa: A Systematic Review. PLoS ONE, 9, e92846. http://dx.doi.org/10.1371/journal.pone.0092846

[23] Njelekela, M.A., Negishi, H., Nara, Y., Sato, T., Tomohiro, M., Kuga, S. and Yamori, Y. (2002) Obesity and Lipid Profiles in Middle Aged Men and Women in Tanzania. East African Medical Journal, 79, 58-64. http://dx.doi.org/10.4314/eamj.v79i2.8901

[24] Muhihi, A.J., Njelekela, M.A., Mpembeni, R., Mwiru, R.S., Mligiliche, N. and Mtabaji, J. (2012) Obesity, Overweight, and Perceptions about Body Weight among Middle-Aged Adults in Dar es Salaam, Tanzania. ISRN Obesity, 2012, Article ID: 368520 . http://dx.doi.org/10.5402/2012/368520

[25] Department of Health (1998) South African Demographic and Health Survey. Department of Health, Pretoria.

[26] Lahmam, A., Baali, A., Hilali, M.K., Cherkaoui, M., Chapuis-Lucciani, N. and Boëtsch, G. (2008) Obesity, Overweight and Body-Weight Perception in a High Atlas Moroccan Population. Obesity Reviews, 9, 93-99. http://dx.doi.org/10.1111/j.1467-789X.2007.00413.x

[27] Walker, A.R.P., Adam, F. and Walker, B.F. (2001) World Pandemic of Obesity: The Situation in Southern African Populations. Public Health, 115, 368-372. http://dx.doi.org/10.1038/sj.ph.1900790

[28] Wang, Y., Liang, H. and Chen, X. (2009) Measured Body Mass Index, Body Weight Perception, Dissatisfaction and Control Practices in Urban, Low Income African-American Adolescents. BMC Public Health, 9, 183. http://dx.doi.org/10.1186/1471-2458-9-183

[29] Neumark-Sztainer, D., Falkner, N., Story, M., Perry, C., Hannan, P.J. and Mulert, S. (2002) Weight-Teasing among Adolescents: Correlations with Weight Status and Disordered Eating Behaviors. International Journal of Obesity, 26, 123-131. http://dx.doi.org/10.1038/sj.ijo.0801853

[30] Emslie, C., Hunt, K. and Macintyre, S. (2001) Perception of Body Image among Working Men and Women. Journal of Epidemiology and Community Health, 55, 406-407. http://dx.doi.org/10.1136/jech.55.6.406

[31] Khawaja, M. and Afifi-Soweid, R.A. (2004) Images of Body Weight among Young Men and Women: Evidence from Beirut, Lebanon. Journal of Epidemiology and Community Health, 58, 352-353. http://dx.doi.org/10.1136/jech.2003.010785

[32] Peltzer, K. and Pengpid, S. (2011) Overweight and Obesity and Associated Factors among School-Aged Adolescents in Ghana and Uganda. International Journal of Environmental Research and Public Health, 8, 3859-3870. http://dx.doi.org/10.3390/ijerph8103859

[33] Amoah, A.G. (2003) Socio-Demographic Variations in Obesity among Ghanaian Adults. Public Health Nutrition, 6, 751-757. http://dx.doi.org/10.1079/PHN2003506

[34] Rguibi, M. and Belahsen, R. (2004) Overweight and Obesity among Urban Sahraoui Women of South Morocco. Ethnicity Diseases, 14, 542-557.

[35] Zinyowera, T. and Msamati, B.C. (1994) Obesity: Is It a Problem in Black Africans in Zimbabwe? Central African Medical Journal of Medicine, 40, 33-38.

[36] Rosenstock, I.M., Strecher, V.J. and Becker, M.H. (1988) Social Learning Theory and the Health Belief Model. Health Education \& Behavior, 15, 175-183. http://dx.doi.org/10.1177/109019818801500203

[37] International Diabetes Federation, IDF (2012) IDF Diabetes Atlas. 5th Edition. 2012 Update. http://www.idf.org/diabetesatlas

[38] Faber, M. and Kruger, H.S. (2005) Dietary Intake, Perceptions Regarding Body Weight, and Attitudes toward Weight Control of Normal Weight, Overweight, and Obese Black Females in a Rural Village in South Africa. Ethnicity \& Diseases, 15, 238-245.

[39] Kumanyika, S., Wilson, J.F. and Guilford-Davenport, M. (1993) Weight-Related Attitudes and Behaviours of Black Women. Journal of American Diet Association, 93, 416-422. http://dx.doi.org/10.1016/0002-8223(93)92287-8

[40] Kruger, R., Kruger, H.S. and Macintyre, U.E. (2006) The Determinants of Overweight and Obesity among 10-15 Year Old School Children in the North-West Province. The THUSA BANA Study. Public Health Nutrition, 9, 351-358. http://dx.doi.org/10.1079/PHN2006849 